\title{
The effect of myo-inositol treatment on basement membrane thickening in the $\mathrm{BB} / \mathrm{W}$-rat retina
}

\author{
Subrata Chakrabarti ${ }^{1}$ and Anders A.F. Sima ${ }^{2}$ \\ 'Department of Pathology, University of Manitoba, Winnipeg, MB, Canada, and ${ }^{2}$ Departments of Pathology and Internal Medicine, \\ and Michigan Diabetes Research and Training Center, University of Michigan, Ann Arbor, MI, USA
}

(Received 10 June 1991)

(Accepted 10 November 1991)

\section{Summary}

A polyol-pathway related perturbation of myo-inositol metabolism has been invoked in the pathogenesis of diabetic complications, including retinal microvasculopathy. Previous studies have demonstrated a beneficiary effect of aldose reductase inhibition on basement membrane thickening of retinal microvessels in diabetic animals. In the present study we demonstrate a significant but partial effect on basement membrane thickening following myo-inositol supplementation. Qualitative structural changes, such as nodular swellings, fibrillar changes and basement membrane projections were not effected by myo-inositol supplementation, suggesting that although abnormal myo-inositol tissue levels may play a role in basement membrane thickening, other factors may be of primary pathogenetic importance.

Key words: Retinal microangiopathy; Basement membrane thickening; Myo-inositol; BB/W-rat

\section{Introduction}

Metabolic derangements secondary to hyperglycemia, such as activation of the polyol-pathway and the associated decrease in tissue myo-inositol (MI) levels have been suggested as major pathogenetic factors in the development of secondary complications in diabetes $[1,2]$. The key enzyme in the polyol-pathway, aldose reductase, is present in retinal endothelial cells and pericytes [3]

Correspondence to: Dr. Anders A.F. Sima, Michigan Diabetes Research and Training Center, The University of Michigan, 1331 E. Ann Street, Room 5111, Ann Arbor, MI 48109-0580, U.S.A. and shows a 3-fold increase in gene expression in the retina of diabetic $\mathrm{BB} / \mathrm{W}$-rats [4]. The demonstration of elevated sorbitol and decreased myoinositol levels in association with increased vascular permeability in the retina of diabetic rodents, as well as the responsiveness of vascular damage to aldose-reductase inhibition or myoinositol supplementation lend further support to the polyol-pathway/myo-inositol theory $[5,6]$. We have previously demonstrated a complete prevention of basement membrane thickening (BMT) in the deep capillary bed of the diabetic $\mathrm{BB} / \mathrm{W}$-rat retina following 6 months of aldose reductase inhibitor (ARI)-treatment. Vigorous insulin-treatment for the same duration prevented 
BMT in both the superficial and deep capillary beds [7] suggesting that proposed mechanisms such as an augmented polyol-pathway [8,9], nonenzymatic glycation [10], or decreased production of specific proteoglycans [11], may be modified by topographic differences [7].

In the present study we examined the effect of myo-inositol supplementation on BMT, in order to explore as to whether the effect of ARI-treatment on BMT is mediated by a normalization of the myo-inositol metabolism, or if this effect is a consequence of the sorbitol lowering effect.

\section{Materials and Methods}

\section{Animals}

Pre-diabetic male $\mathrm{BB} / \mathrm{W}$-rats and age-matched non-diabetes-prone male $\mathrm{BB} / \mathrm{W}$-rats were obtained from the NIH-Colony at the University of Massachusetts, Worcester, M $\Lambda$. To ascertain onset of diabetes, diabetes-prone animals were monitored daily with respect to glucosuria (Test Tape, Eli Lilly Canada, Inc., Toronto, Ont). After detection of glucosuria diabetic rats were started on small daily doses $(0.5-3.0 \mu /$ day $)$ of protamine zink insulin (PZI) (Connaught-Novo Inc. Toronto, Ont.). Three weeks after onset of diabetes, the rats were randomly assigned as follows: non-diabetic control rats, $n=5$; diabetic insulin-deficient rats maintained on small doses of PZI, $n=5$; and diabetic insulin-deficient rats maintained on PZI and fed a $1 \%$ myo-inositol supplemented diet, $n=5$. All animals were maintained in individual air-filtered metabolic cages with free access to rat-chow (non-MIsupplemented chow contained $0.05 \% \mathrm{MI}$ ) (Lab Blox F-6, Wayne Animal Diets, Winnipeg, MB, Canada) and water. Blood glucose levels were examined every second week and glycated hemoglobin every 3 months as previously described [7]. Five animals from each group were sacrificed after 6 months of diabetes.
Tissue collection

Animals were anesthetized with pentobarbital sodium ( $50 \mathrm{mg} / \mathrm{kg}$ body weight) and perfused with $2.5 \%$ glutaraldehyde in cacodylate buffer (pH 7.4). Retinal segments within $3 \mathrm{~mm}$ of the optic nerve head were taken from the superior temporal quadrant. The tissues were processed and examined electron microscopically as previously described [7].

\section{Morphometric examination}

Twenty cross-sectioned capillaries, 10 from the superficial capillary bed and 10 from the deep capillary bed, were examined in each animal. Capillary basement thickness, pericyte and endothelial cell profile areas and lumenal areas (expressed as percentages of total capillary area), and number of pericyte profiles and endothelial cclls per capillary were calculated as previously described in detail [12].

Each capillary was examined for the presence of basement membrane abnormalities (nodular swellings, laminated basement membranes, and fibrillary material, [7]), and basement membrane projections. These changes were expressed as a percentage of capillaries showing the abnormalities. The mean value of basement membrane abnormalities was obtained in each capillary bed in individual animals. The investigator (S.C.) was unaware of the identity of the tissue samples.

\section{Statistical analysis}

The data are expressed as mean \pm SEM. One way analysis of variance with linear contrast, and linear regression by least squares were used for data analysis.

\section{Results}

\section{Clinical data}

MI-treated and untreated diabetic rats showed significantly lower body weights $(P<0.001)$ 
compared to non-diabetic control rats $(392.0 \pm$ 16.6 and $382.4 \pm 12.4$ vs $497.0 \pm 6.5 \mathrm{~g}$ respectively). They showed elevated blood glucose levels $(P<0.002)(22.0 \pm 2.1$ and $20.8 \pm 2.1$ vs 8.1 $\pm 1.3 \mathrm{mmol} / 1$, respectively) and increased glycated hemoglobin levels $(P<0.002)(9.7 \pm$ 0.9 and $10.9 \pm 1.6$ vs $3.9 \pm 0.1 \%$, respectively).

\section{Vascular morphometry}

In control as well as diabetic animals the BMT of the superficial capillaries was greater than that of the deep capillaries. MI-treatment showed a significant $(P<0.001)$ but only partial prevention of BMT of the deep capillaries, and had no effect on BMT in superficial capillaries. Structural basement membrane abnormalities were not prevented by MI-treatment nor did this regimen have an effect on basement membrane projections (Table 1). Endothelial cell and pericyte morphometry was not altered by diabetes or MI-treatment (data not shown). Regression analysis of BMT with blood glucose concentrations and glycated hemoglobin levels as independent variables revealed significant positive relationships for both capillary beds (Fig. 1).

\section{Discussion}

The mechanisms responsible for basement membrane thickening in diabetes remain obscure. The only hard evidence at hand is that hyperglycemia is somehow required for the accelerated basement membrane thickening as substantiated by the data in the present study. The possibility that this adverse effect of hyperglycemia may at least in part be mediated by an increased activity of the polyol-pathway, is supported by a similar thickening of the retinal capillary basement membranes in galactosemic animals, that is prevented by aldose reductase inhibition [8]. We [7] and others [13] have previously reported that inhibition of the polyol-pathway prevents the BMT in diabetic rats. However, this preventive effect does not appear to be universal, since in our previous study [7] a complete inhibition was achieved only in the deep capillaries of the retina

\section{TABLE 1}

Basement membrane thickness (BMT), basement membrane (BM) abnormalities and projections in control, diabetic and MI-supplemented diabetic BB/W-rats

\begin{tabular}{|c|c|c|c|}
\hline & $\mathrm{BMT} \mathrm{nm}$ & BM abnormalities & BM projections \\
\hline \multicolumn{4}{|l|}{ Superficial capillary bed } \\
\hline \multirow[t]{2}{*}{ Control rats $(n=5)$} & $\ulcorner-129.1 \pm 5.5$ & $\ulcorner\quad 2.0 \pm 2.0$ & 0 \\
\hline & $P<0.001$ & $P<0.01$ & \\
\hline Diabetic rats $(n=5)$ & $-162.6 \pm 6.7$ & $-24.0 \pm 5.0$ & $2.0 \pm 2.0$ \\
\hline Diabetic + MI rats $(n=5)$ & $-160.8 \pm 8.2$ & $22.4 \pm 5.7$ & $6.2 \pm 3.8$ \\
\hline \multicolumn{4}{|l|}{ Deep capillary bed } \\
\hline \multirow[t]{2}{*}{ Control rats $(n=5)$} & $\lceil 86.4 \pm 5.7$ & $10.0 \pm 6.3 \neg$ & $6.0 \pm 2.5$ \\
\hline & $P<0.001$ & $P<0.01$ & \\
\hline Diabetic rats $(n=5)$ & $\begin{array}{r}-120.2 \pm 4.87- \\
P<0.001\end{array}$ & $80.0 \pm 6.3-$ & $6.0 \pm 4.0$ \\
\hline Diabetic + MI rats $(n=5)$ & $-105.6 \pm 4.9-$ & $66.0 \pm 6.9$ & $1.8 \pm 1.8$ \\
\hline
\end{tabular}



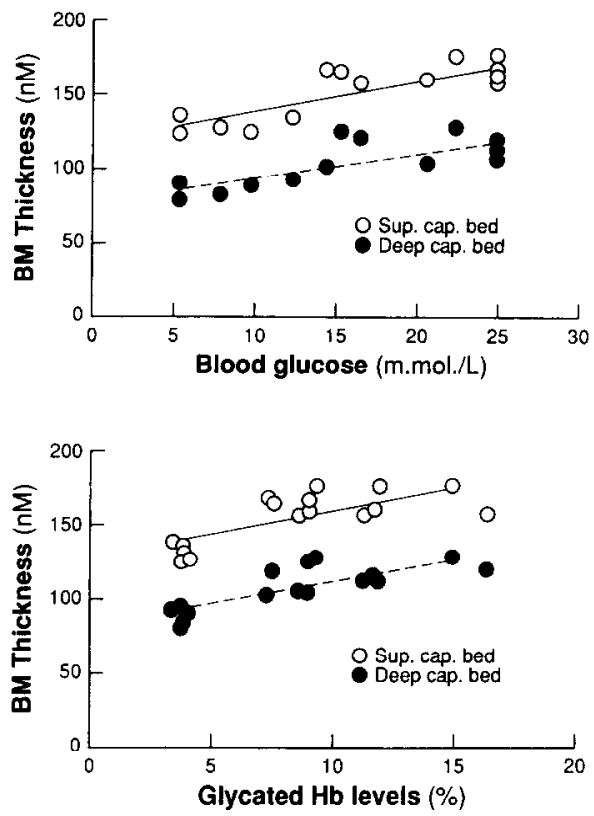

Fig. 1. Regression analysis of retinal capillary BM thickness with (top) blood glucose levels as the independent variable ( $r=0.8, P<0.001$ for superficial and $r=0.75, P<0.005$ for deep capillary bed) and (bottom) glycated $\mathrm{Hb}$ levels as the independent variable $(r=0.75, P<0.005$ for superficial and $r=0.78, P<0.001$ for deep capillary hed).

but not in the superficial capillaries, despite similar immunoreactivity in the two capillary beds [3]. These findings suggest, if indeed the polyolpathway activation and subsequent metabolic abnormalities play a major role in BMT, that the activity of the rate limiting enzyme aldose reductase, or its enzyme kinetics may vary greatly from one capillary bed to another. The failure of an ARI to show an effect on skeletal muscle capillary basement membrane in diabetic subjects would seem to support this notion [14].

In the present study MI-supplementation had a significant but only partial preventive effect on BMT in the deep capillary bed of the diabetic retina in the $\mathrm{BB} / \mathrm{W}$-rat. This would indicate that at least part of the complete prevention achieved following ARI-treatment in the same capillary bed is mediated by an effect of the polyol-pathway on MI-metabolism, or alternatively that a $1 \%$ MIsupplementation was insufficient to normalize the MI pool. The latter explanation is unlikely, how- ever, since Tilton et al. [15] recently demonstrated a non-significant prevention of BMT in the deep capillary bed of STZ-diabetic rats following 9 months of a $2 \%$ MI supplemented diet.

The positive relationship between blood-glucose levels and BMT in both diabetic rodents [7] and man [14], may suggest that non-enzymatic linkage between extracellular matrix proteins and various hexoses could be mainly responsible for BMT, as suggested by Brownlee et al. [10].

This notion is in keeping with our previous suggestion that the demonstrated effect of ARI on BMT [7] may be mediated by a diminished production of fructose by the polyol-pathway, since it has been demonstrated that fructose is a potent glycator of structural proteins [16].

In summary, the present study has demonstrated a significant effect of myo-inositol supplementation on BMT in the diabetic BB/W-rat retina. However, the exact mechanism by which this is achieved remains to be investigated.

\section{Acknowledgements}

These studies were supported by grants from the Medical Research Council of Canada (MT10673; MT-10679) and NIH (DK-3830475). We are grateful to Mrs. Ning Ma for technical assistance, and to Ms. Annette McArthur for preparing the manuscript.

\section{References}

I K. Winegrad, A.L. (1987) Does a common mechanism induce the diverse complications of diabetes? Diabetes $36,396-406$.

2 Greene, D.A., Lattimer, S.A. and Sima, A.A.F. (1988) Are disturbances of sorbitol, phosphoinositide and $(\mathrm{Na}, \mathrm{K})$-ATPase regulation involved in the pathogenesis of diabetic neuropathy? Diabetes 37, 688-693.

3 Chakrabarti, S., Sima A.A.F., Nakajima, T., Yagihashi, S. and Greene, D.A. (1987) Aldose reductase in the BBrat: isolation, immunological identification and localization in the retina and peripheral ncrve. Diabetologia $30,244-251$. 
4 Ghahary, A., Murphy, L.J., Chakrabarti, S. and Sima, A.A.F. (1990) The effects of insulin and aldose reductase (AR) inhibitor treatment on AR expression. Diabetes 39 (suppl. 1) 61A (abstracts).

5 Tilton, R.G., Chang, K., Puglisse, G., Eades, D.M., Province, M.A., Sherman, W.R., Kilo, C. and Williamson, J.R. (1989) Prevention of hemodynamic and vascular albumin filtration in diabetic rats by aldose reductase inhibitors. Diabetes 37, 1258-1270.

6 Puglisse, G., Tilton, R.G., Speedy, A., Santarelli, E., Eades, D.M., Province, M.A., Kilo, C., Sherman, W.R. and Williamson, J.R. (1990) Modulation of hemodynamic and vascular filtration changes in diabetic rats by dietary myo-inositol. Diabetes 39, 112-122.

7 Chakrabarti, S. and Sima, A.A.F. (1989) Effect of aldose reductase inhibition and insulin treatment on retinal capillary basement membrane thickening in BB-rats. Diabetes 38. 1181-1186.

8 Robison, W.G. Jr., Kador, P.F. and Kinoshita, J.H. (1983) Retinal capillaries: basement membrane thickening by galactosemia prevented with aldose reductase inhibitor. Science 221, 1177-1179.

9 Robison, W.G. Jr., Kador, P.F., Akagi, Y., Kinoshita, J.H., Gonzalez, R.I. and Dvornik, D. (1986) Prevention of basement membrane thickening in retinal capillaries by a novel inhibitor of aldose reductase, Tolrestat. Diabetes 35, 295-299.

0 Brownlee, M., Cerami, A. and Vlassara, H. (1988) Advanced products of nonenzymatic glycosylation and the pathogenesis of diabetic vascular disease. Diabetes Metab. Rev, 4, 437-457.
11 Chakrabarti, S., Ma, N. and Sima, A.A.F. (1991) Anionic sites in diabetic basement membranes and their possible role in diffusion barrier abnormalities. Diabetologia 34, 301-306.

12 McEwen, T.A.J., Chakrabarti, S and Sima, A.A.F. (1987) A rapid reproducible method for measurement of basement membrane thickness in the biological structures. Comput. Biol. Med. 17, 193-197.

13 Chandler, M.L., Shannon, W.A. and DeSantier, L. (1984) Prevention of retinal capillary basement membrane thickening in diabetic rats by aldose reductase inhibitors. Invest. Ophthalmol. Vis. Sci. 25, (suppl.) 159 (abstract).

14 Ramirez, L.C., Arauz, C., Pruneda, L., Hammon, K., Rosenstock, J. and Raskin, P.H. (1991) The effect of aldose reductase inhibition with ponalrestat on the width of the capillary basement membrane in diabetes mellitus. Diabetes Res. Clin. Prac. 11, 73-80.

15 Tilton, R.G., Faller, A.M., LaRose, L. and Williamson, J.R. (1991) Diabetes induced retinal capillary basement membrane thickening despite dietary myo-inositol supplementation. Invest. Ophthalmol. Vis. Sci. 32 (suppl.) 1128 (abstract).

16 Grandhee, S.K., Sell, D.R. and Monnier, V.M. (1991) Mechanism of formation of the tissue matrix crosslinks pentosidine. Diabetes 40 (suppl.) 203A (abstract).

17 Bagnosco, S.M., Murphy, H.R., Bedford, J.J. and Burg, M. (1988) Osmoregulation by slow changes in aldose reductase and rapid changes in sorbitol flux. Am. J. Physiol. 254, C788-C792. 